\title{
PELO ENSINO PÚBLICO, LEIGO E GRATUITO
}

Marta Maria Chagas de Carvalho(1)

RESUMO: $O$ artigo propõe que a laicidade do ensino seja considerada, no contex to do atual processo constituinte, questão decisivamente relevante para a definição do cará. ter da educacaão pública, numa sociedade de. mocrática. Com esta finalidade, examina o sentido político que assumiu a defesa da escola leiga, nos anos 30. Em seguida, retoma a questão nos debates constitucionais em curso, criticando a posição da Igreja Católica em favor da destinação de recursos públicos para escolas confessionais.
ABSTRACT: The article argues that the question of secularity of education should be considered lin the context of today's constitutional debates) to be of decisive importance for the definition of public education in a democratic society. With this aim in mind, the article examines the political significance of the defence of lay schools in Brazil in the 1930's. It goes on to reconsider the same problem in today's consti. tutional debates, criticising the Catholic Church's defence of the use of public money for the support of religious schools.

Em fevereiro de 1934, realiza-se em Fortaleza a VI Conferência Nacional de Educação, promovida pela Associação Brasileira de Educação - A.B.E., fundada no Rio de Janeiro em 1924 por um grupo de intelectuais convictos de que na educação residia a chave para a solução dos problemas brasileiros. A Conferência é palco de conflito acirrado entre os defensores do ensino laico, então sediados na A.B.E., e católicos, aliados a integralistas.

A sessão de 7 de fevereiro chegou a ser suspensa. Noticia um jornal carioca:

"A segunda parte da sessão foi tumultuada devido a haver um dos delegados presentes proposto a adoção do sistema integralista nas escolas cearenses. $O$ salão se achava apinhado de elementos pertencentes à Legião Integralista, de modo que o orador foi entusiasticamente aplaudido por seus correligionários. Um tal ambiente animou o delegado espírito-santense sr. Cyro Vieira, a propor fosse enviado, em forma de apelo, um telegrama à Assembléia Constituinte, solicitando a instituição do ensino religioso obrigatório nas escolas públicas. Estribando-se nos dispositivos do regimento

(1) Professora-assistente-doutora no Departamento de Filosofia e Ciências da Educação da Faculdade de Educação da USP. 
Interno, manifestaram-se contrários à proposta o sr. Sussekind de Mendonça, da delegação carioca e vários outros. Nessa ocasião, d. Xavier de Mattos, padre beneditino e representante do ministro Washington Pires no Congresso, tomou a palavra para apoiar a proposta por entre as ruidosas manifestações dos elementos integralistas que enchiam as filas de cadeiras destinadas à assistêncial. .) Como fosse impossivel restabelecer a ordem, o sr. Moreira de Souza suspendeu a sessão" (1)

A intervenção de Sussekind de Mendonça, sustando as pretensões dos proponentes do ensino religioso, desencadeia reação violenta na imprensa cearense alinhada ao integralismo e ao catolicismo. Com a intervenção de Sussekind, escrevia um jornal, "o comunismo arvorou o seu estandarte rubro na Escola Normal Pedro /I", sede da Conferência, fazendo emergir "imundícies precipitadas" "detritos pestilenciais" que jaziam latentes sob "as águas paradas" dos debates educacionais.

Edgar Sussekind de Mendonça, um dos fundadores da A.B.E., era membro do Conselho Diretor da associação e um dos signatários do Manifesto dos Pioneiros da Educação Nova. Aos ataques que sofreu da imprensa integralista e católica se contrapuseram inúmeras manifestações de solidariedade de outros órgãos da imprensa, sindicatos e movimentos. Entre elas, uma homenagem promovida pela Coligação Nacional pró Estado Leigo, que coordenava as organizações laicistas no País. A homenagem valeu-lhe um atentado de grupos radicais que se afirmaram católicos, sublevados pelo teor do noticiário do jornal $O$ Nordeste a respeito do discurso que Sussekind nela teria proferido. Abusando da "hospitalidade cearense" derramando "toda a sua vesânia comunista contra a pessoa divina e adorável de Nosso Senhor Jesus Cristo" Sussekind era "um estrangeiro de alma e de nome" que vinha "do Sul" a "titulo de pedagogo" impregnar "o povo cearense com doutrinas dissolventes"

A VI Conferência Nacional de Educação é realizada num momento em que, paralelamente aos debates em torno da Constituição, acirram-se as disputas doutrinárias entre os defensores da chamada "escola nova" e os católicos apologistas da "escola espiritualista reformada" As "doutrinas dissolventes" que O Nordeste exorciza de-

(1) As noticias de jornal citadas neste artigo constam da pasta relativa a VI Conferência Na. cional de Educação existente nos Arquivos da Associação Brasileira de Educação, no Rio de Janeiro. Os recortes arquivados não identificam o jornal de origem. 
signavam o que era batizado pelos católicos de "naturalismo pećagógico" Os propósitos escolanovistas de derivar os métodos educativos do conhecimento da natureza do aluno tal como era constituída pelas ciências pedagógicas haviam sido repudiados por Pio $X I$ na Encíclica Divini Illius Magistri. O naturalismo pedagógico feria "o fim e a forma própria da educação cristã, conforme a ordem estabelecida por Deus na economia da sua Providência" (Schola, 1930, p. 121). Interessava aos católicos moldar a prática educativa, fixando-Ihe procedimentos e finalidade. Incomodava-os, especialmente, a rejeição da autoridade do professor na relação com o aluno e a negação do finalismo religioso para todo processo educativo. $\mathrm{O}$ ensino religioso era, assim, apenas uma das medidas que a "escola espiritualista reformada" avançava. Sua simples introdução nas escolas era, entretanto, suficiente para comprometer o projeto escolanovista naquilo que tinha de inaceitável para os educadores católicos.

Os católicos não foram, como quiseram fazer crer seus adversários, tão indiscriminadamente resistentes às então novas doutrinas pedagógicas. Também os chamados "liberais" na maioria dos casos, não endossavam, como alardeavam seus opositores, o chamado "naturalismo pedagógico" com todas as suas implicações. O movimento pela renovação educacional contou, na década de 20 , com o apoio entusiástico de muitos católicos. Foi somente a partir de 1929, depois da publicação da Divini lllius Magistri, que eles começaram a distinguir no emaranhado das propostas escolanovistas o que era ou não compativel com sua crença. Quanto à maior parte dos chamados "liberais" estavam mais próximos de seus adversários do que a historiografia educacional tem feito acreditar.

Desde a década de 20 se consolidava, entre os grupos que se contraporiam a partir de 1930 na luta pelo controle do sistema educacional, a crença de que da educação dependia a resolução dos problemas sociais, políticos e econômicos do País. O consenso existente quanto ao poder atribuído à educação, em 20 , juntava católicos, positivistas e liberais num projeto cujo denominador comum era a ênfase no papel moralizador da educação. As campanhas de alfabetização desencadeadas por organizações interessadas em reordenar o sistema político através do voto secreto refluíram, em meados da década, cedendo lugar para movimentos em favor do que se entendia por "educação integral" Um educador do período, Heitor Lyra da Silva, fundador da A.B.E., considerava a "instrução pura e simples" uma "arma" que era, "como toda arma, perigosa" (Silva, s/d, p. 65). Colocá- 


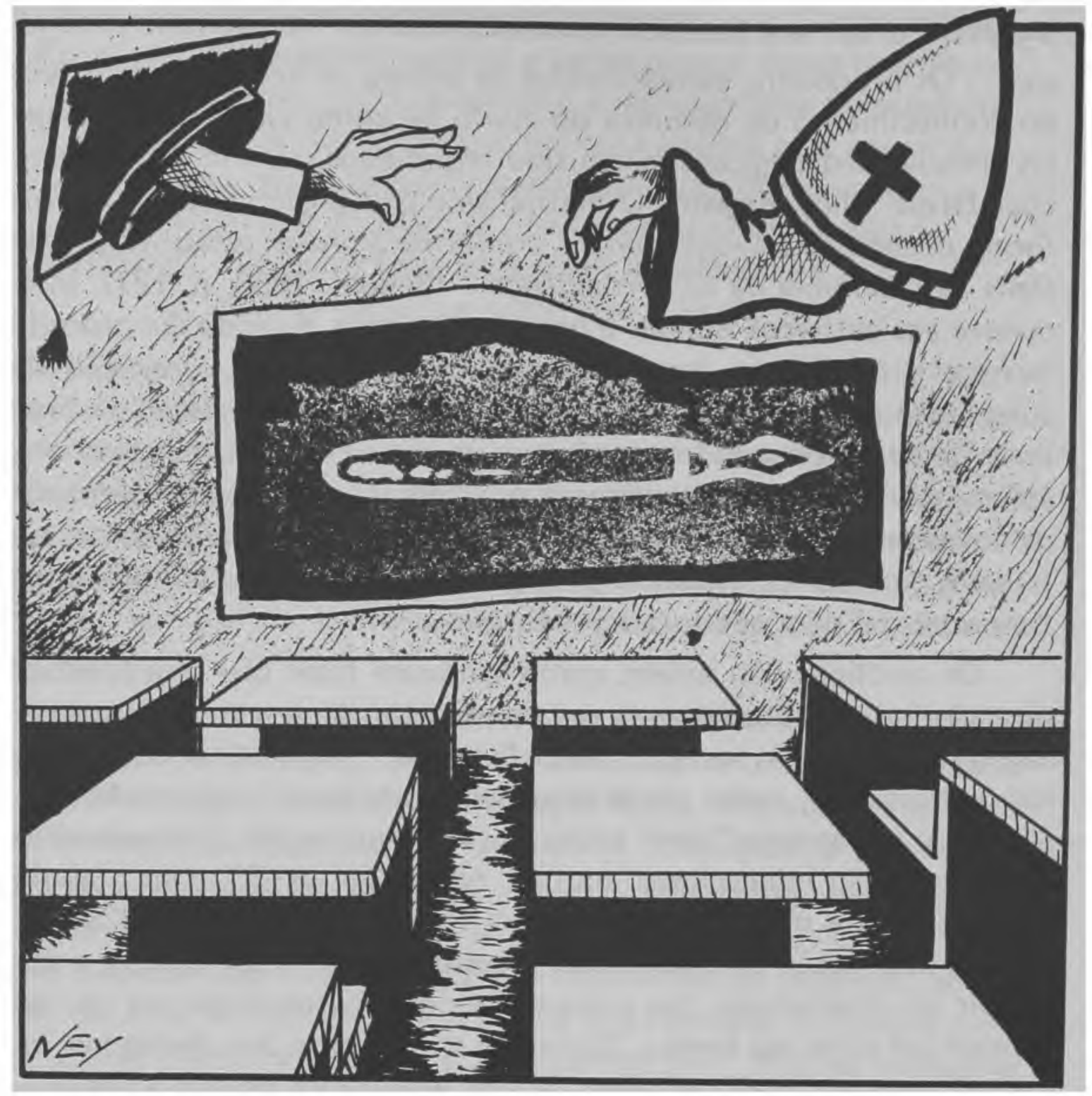

la nas mãos da população requeria medidas que preparassem quem a recebesse para seu adequado manejo. Tais medidas apareciam, para Belisário Penna, higienista-educador, como garantia do "trabalho metódico, adequado, remunerador e salutar" de "disciplina consciente $e$ voluntária e não apenas automática e apavorada" como também da "ordem sem necessidade do emprego da força e de medidas restritivas ou supressivas da liberdade" (Penna, 1968, p. 69).

A proposta de uma "educação integral" era uma das respostas políticas ensaiadas por setores da intelectualidade brasileira na redefinição dos esquemas de dominação vigentes. Tratava-se, primordialmente, de estruturar mecanismos que garantissem formas mais modernas de controle nas cidades, que equivalessem ao papel desempenhado pelo coronelismo no campo. A presença cada vez mais sensível 
da fábrica na vida dos centros mais populosos, produzindo a seu redor um espaço de concentração de operários e desocupados, fazia com que a educação aparecesse como recurso importante de disciplinarização dos costumes, viabilizando a convivência interclasses no espaço urbano e no tempo da produção/expropriação capitalista. Esta potencialidade da educação era enunciada por Gustavo Lessa que, fazendo analogia da situação do Rio de Janeiro em 1920 com a de Londres no início da industrialização, escrevia:

"Há mais de um século, quando a cidade começou a se industrializar, nela despontaram os mesmos males que hoje

vemos afluir ao Rio de Janeiro: miséria em vasta escala, superlotação das habitações, facilidade de contágios em doenças, degradação dos padrões da moralidade. Mas a raça inglesa soube suscitar então os leaders enérgicos que ela tem produzido em todas as emergências, não só religiosos como leigos. Foi-se organizando a resistência, foram-se constituindo inúmeras sociedades privadas para lutar contra a miséria física e moral. Está claro que os males não foram extintos, mas opôs-se à sua violenta invasão a muralha de aço da solidariedade humana. Pode-se dizer que em todo esse movimento coube um papel proeminente à educação. (Lessa, 1930, p. 208).

A formulação ideológica mais disseminada na década de 20 do papel moralizador atribuído à educação deu-se no âmbito do nacionalismo que contamina toda a produção cultural do período. Neste âmbito, o papel da educação é hiperdimensionado: tratava-se de dar forma ao País amorfo, de transformar os habitantes em povo, de vitalizar o organismo nacional, de erradicar a doença e o vício das populações brasileiras, formando corpos vigorosos, produtivos e disciplinados. Propor a educação como "o grande problema nacional" - proposta que caracteriza o que Jorge Nagle chamou de "entusiasmo pela educação" dos anos 20 - era projeto político autoritário: obra de moldagem do povo, matéria este informe e plasmável conforme os desígnios de uma elite que se auto-investia de poder e autoridade para promovê-la.

O consenso quanto ao papel moralizador da educação e à sua propalada importância para o que se entendia como formação da nacionalidade só implodiu na década de 30 , quando, depois do movimento de outubro, as divergências passaram a ser mais relevantes que as concordâncias, na disputa pelo controle do sistema educacional. 
Até então, apenas alguns acidentes de percurso tinham abalado a unidade do movimento, em situações nas quais a educação moral ou o patriotismo preconizados eram traduzidos pelos grupos que o integravam em termos que ameaçavam o consenso existente. É o caso, por exemplo, de diversas investidas que traduziam o patriotismo a ser inseminado nos bancos escolares de modo que ele incorporasse a tradição católica como elemento constitutivo da alma nacional a ser neles encarnada. É o caso também de outras investidas que faziam equivaler educação moral e educação religiosa despertando a indignação dos partidários da moral leiga. É o caso, ainda, dos esforços em demonstrar que a educação religiosa era ingrediente do que se receitava como educação integral.

É na IV Conferência Nacional de Educação, realizada em dezembro de 1931, que o movimento educacional se fratura. $E$ isto porque o grupo que lançaria o Manifesto dos Pioneiros da Educação Nova, em 1932, tem então a clara percepção de que o movimento abrigava projetos pedagógicos politicamente inconciliáveis. A presença de Getúlio Vargas e Francisco Campos na Conferência, pedindo aos conferencistas que formulassem "o sentido pedagógico" da Revolução, fornecendo-Ihe a "substância" o "conceito" da educação e também a "fórmula mais feliz" da política educacional, é recebida com desconfiança pelo grupo. É que lideranças católicas tinham um lugar de fala privilegiado na Conferência, o que permitiria, segundo Nóbrega da Cunha, que atuassem como "guias" como "orientadores da Assembléia" fixando, pela respeitabilidade de que gozavam, "verdadeiros rumos para os debates em plenário" (Cunha, 1932, p. 23). Responsável por levantar, na Conferência, a questão de ordem a respeito da pertinência de uma resposta a Getúlio Vargas e seu ministro, Nóbrega da Cunha localiza com clareza o sentido político da atuação daquelas lideranças. Diz ele que uma delas, Fernando Magalhães, cujo poder de pressão derivava de ser o presidente da Conferência, além de reitor da Universidade do Rio de Janeiro, traçara em sua fala, na abertura do congresso, uma orientação doutrinária clara e definida:

"educação católica, formação do povo no sentido iniciado pelos jesuítas, para transformar o Brasil em imenso campo de procissão por onde as multidões do futuro, como a gente bugre do passado, transitassem acompanhando, submissamente, alguma nova figura de missionário roto, esquálido, descalço e dilacerado, a caminho de seu destino imortal. " "(Cunha, 1932, p. 70). A fala de Magalhães o qual a Antropofagia Cultural já recomendara como sobremesa 
para os primitivos da nova era - podia ser interpretada como "a fórmula de uma sugestão destinada a encaminhar a assembléia em linha reta para o ensino religioso, pois querendo esboçar o quadro da

evolução brasileira, estabeleceu como ponto inicial da nossa formação de povo a obra da Catequese e indicou a Cruz como único marco para a finalidade dos nossos destinos nacionais" (Cunha, 1932, p. 67).

A intervenção de Nóbrega da Cunha na IV Conferência é que abre espaço político para o lançamento do Manifesto dos Pioneiros da Educação Nova, considerado como um dos principais marcos da luta pela escola pública leiga e gratuita no País. Lançado no ano seguinte, é apresentado como a resposta que a Conferência não dera ao governo. Seus desdobramentos são bastante conhecidos. Haverá, a partir đele, dois campos nitidamente diferenciados de luta pelo controle do sistema de ensino. Isto possibilitou que a A.B.E. se constituísse como o principal suporte institucional da luta pelo ensino público leigo e gratuito, garantindo, na Constituição de 1934, a vitória de grande parte de suas propostas. Não a vitória da laicidade do ensino. As pressões reacionárias prevaleceram logrando, inclusive, alijar do meio educacional e da vida política, a partir de 1935 , os seus mais intransigentes defensores, como foi o caso de Anísio Teixeira e Edgar Sussekind de Mendonça. Prevaleceram também fazendo com que com a colaboração de alguns signatários do Manifesto já então alinhados ao Estado Novo - se sedimentasse uma memória sobre o movimento educacional nas décadas de 20 e 30 na qual foi descaracterizada a sua dimensão política e minimizada a questão da laicidade da escola. Veja-se, por exemplo, a narrativa de Fernando de Azevedo, elaborada durante o Estado Novo:

"Não se pode, porém, circunscrever o domínio dessas lutas, no terreno pedagógico, a uma discordância ou oposição entre a política escolar da Igreja e a nova política de educação que adotava, como pontos de programa, alguns princípios repelidos por aquela, como a coeducação e a laicidade do ensino. Essas lutas complicaram-se sem dúvida, tornando mais ásperas e acesas, no seu desenvolvimento com o conflito de ideologias, de esquerda e de direita, comunistas e fascistas, que fundaram na Europa, sobre o regime de um partido e em nome de um ideal de classe, raça ou de

nação, e que então repercutiu no Brasil mais ou menos violentamente, pela organização e pelas atividades de partidos extremistas. Mas desencadeadas pela ação da Igreja contra algumas 
das idéias reformadoras; sacudidas e turvadas pelos choques $e$ doutrinas extremadas, e de tentativas de infiltrações de partidos subversivos, essas campanhas de renovação escolar tiveram, nas suas origens e conservaram, em todo o seu curso, a oposição, que é um

fato normal e constante em todas as sociedades, entre novos $\mathrm{e}$ velhos, entre tradicionalistas e renovadores, e que, tendo-se mantido larvada ou mal dissimulada, no primeiro momento, se tornou aberta quando surgiram às circunstâncias favoráveis às represálias e às resistências" (Azevedo, 1943, p. 401).

Não cabe aqui discutir o papel político que o discurso da modernização desempenhou e vem desempenhando no País. Cabe apenas, para as finalidades deste artigo, registrar que as afirmações de Fernando de Azevedo - que não são caso isolado - relativizam a importância de episódios como os até aqui relatados, nos quais se evidencia que o confronto entre laicistas e religiosos nas décadas de 20 e 30 era central e tinha, ele próprio, marcado papel político.

Mais: que pelo menos alguns dos defensores da escola leiga rejeitavam a proposta pedagógica católica enquanto proposta política de regulação das relações humanas na ordem civil.

Hoje, nos debates em torno da elaboração da Carta Constituinte, retorna a questão da laicidade da escola. Associações de profissionais da educação vêm, há alguns anos, defendendo a destinação exclusiva de verbas públicas para escolas públicas e o ensino leigo e gratuito. A elas se juntaram outras entidades e surgiu a proposta de iniciativa popular apresentada pelo Fórum da Educação na Constituinte em Defesa do Ensino Público e Gratuito que representa, entre outras entidades, a ANDE, a ANDES, a OAB, a SBPC, a CUT a CGT e a UNE. As perspectivas de vitória desta proposta não são, entretanto, animadoras. As pressões contrárias à disseminação da escola pública estão organizadas e poderosas. No anteprojeto do relator da Comissão de Sistematização e nas negociações em andamento no interior da Constituinte prevalece a tese de que uma solução conciliatória é proibir a destinação dos recursos públicos apenas para os estabelecimentos escolares de fins lucrativos. Com isso ficariam amparadas por esses recursos as escolas confessionais, filantrópicas e comunitárias, que não tenham o lucro como finalidade. A pseudo-solução conciliatória tem o apoio da Igreja que não vê, assim, ameaçados os seus objetivos confessionais de lucro espiritual. A medida é mesmo preconizada pela CNBB, que encaminhou proposta de iniciativa popular nestes termos. 
Monta-se, portanto, a fórmula que ameaça drenar para fora do sistema público de ensino os já escassos recursos destinados à sua expansão e manutenção. A pressão organizada e agressiva que a Igreja Católica vem aplicando na Constituinte autoriza um grande pessimismo quanto ao destino das verbas públicas. Sua possivel destinação para escolas confessionais traz para o centro do debate a questão da laicidade da escola.

Em artigo recente para a Folha de S. Paulo, Florestan Fernandes denuncia o comportamento da Igreja Católica na Constituinte, vendo nele - "capítulo mais dramático" da reação organizada contra o movimento pela escola pública, leiga e gratuita: "Eis ai o que não se esperava. No fim do século a Igreja Católica continua na mesma disposição que a animava nas ruturas com a $R e$ pública e disputa com $o$ Estado uma fatia de recursos públicos que the faculte o controle de mente e corações" Nessa disputa, prossegue, a lgreja Católica revela a sua "outra face, reacionária e obscurantista, a vocação de ser um império

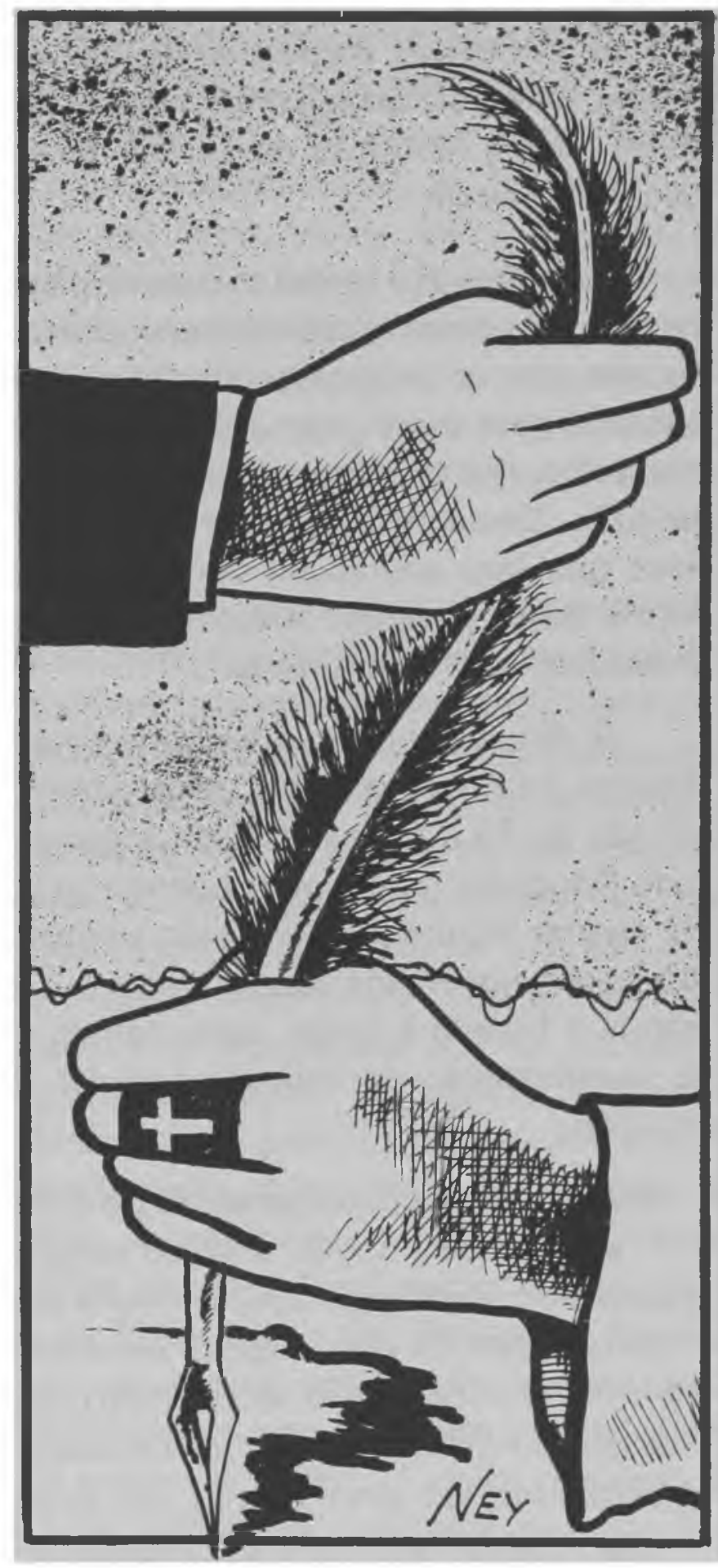
dentro do Estado" (Folha de S. Paulo, 4/8/87). A denúncia de Florestan, lúcida e autônoma, formula o problema em termos adequados. Não é somente o assalto às verbas públicas que se planeja mas 
também um projeto político que se explicita na instrumentalização dos recursos públicos para fins confessionais.

0 desenrolar dos acontecimentos traz de volta, assim, a questão da laicidade da éscolla. A estratégia da Igreja Católica ná Constituinte - que, hoje, significa caminho aberto para a consolidação e expansão de iniciativas confessionais não apenas católicas - requer que a deffesa da escola leiga ganhe o estatuto de questão decisivamente relevante para a definição do caráter da educação pública numa sociedade democrática.

Nos anos 30, as investidas católicas foram identificadas pelos defensores da escola leiga como propostas de inequívoco sentido político, em que se projetava um determinado modelo de sociedade. Era possível para esses grupos liberais fantasmar, então, um Estado neutro, acima dos conflitos sociais, como o educador de um novo tipo de cidadão. Desta posição é que se indignavam contra o assalto dos católicos que thes apareciam como a realização acabada do sectarismo. Ainda desta posição, advogavam a neutralidade doutrinária do que entendiam por "moral leiga"

A situação, hoje, é bastante diversa. Há apenas alguns anos, os debates educacionais vêm relativizando convicções sedimentadas na década de 70 que exorcizavam inapelavelmente a figura liberal do Estado Educador, com apoio nas teorias reprodutivistas, então em voga. Há apenas alguns anos tem sido mitigado o maniqueísmo, largamente difundido nos meios educacionais durante a mesma década, que contrapôs o Estado à Igreja, constituindo esta como lugar por excelência da manifestação da vontade popular. Moacyr de Góes caracteriza a situação:

"Nos dez anos de exacerbação do Estado autoritário de 1964 (isto

é, de 1968 a 1978), a Igreja progressista ofereceu abrigo ao pluralismo ideológico educacional e então se desenhou um esquema maniqueista da vida: a Igreja representaria a sociedade e o Estado significaria a usurpação da vontade popular. Daí teria nascido a visão de que ao Estado faltaria legitimidade para promover a educação. A escola pública seria, apenas, um aparelho ideológico do Estado e o seu objetivo explícito e competentemente operacionalizável, a reprodução" (Góes, 1986, p. 46).

As investidas da Igreja Católica em favor do ensino confessional surpreendem os educadores, assim, numa situação diametralmente 
oposta à da década de 30 . As teses que ela avança, contudo, reeditam a estratégia posta a funcionar em 30 . Porque a proposta de iniciativa popular encaminhada pela Confederação Nacional dos Bispos do Brasil-CNBB não só pleiteia recursos para escolas confessionais como também envereda pelo campo pedagógico, prescrevendo o ensino religioso em termos similares aos de 20 e 30, como ingrediente indispensável para a "educação plena" do indivíduo. Contra tal manifestação de perenidade de propósitos, como poderão reagir os defensores da escola leiga em tempos quando mal acaba de ser redimensionada a desconfiança com relação ao papel do Estado na educação e quando a Igreja Católica colhe os frutos de sua mobilização em favor de causas populares? Em tempos em que a Igreja se impõe como importante aliada para amplos setores de esquerda e como interlocutora do governo nas negociações que vêm definindo o teor da assim chamada transição democrática?

Do paralelo com 30 não resulta apenas uma apreciação pessimista da situação atual. $O$ debate educacional dos últimos vinte anos teve o mérito de desnudar dispositivos escolares de reposição das relações de dominação. Teve-o também ao indagar sistematicamente em nome de que interesses um projeto educacional particular se efetiva. Isto significa que, pelo menos, pode-se ter a esperança de não reeditar o mesmo tipo de entusiasmo pela educação que marcou as décadas de 20 e 30. Mas isto é pouco. Principalmente, pela razão de que, não por qualquer entusiasmo conjunturalmente determinado, mas por secular vocação, a Igreja Católica ocupará o espaço que Ihe for deixado. E oportuno impedir que o direito e o dever do Estado de garantir, com o recurso à escola pública, leiga e gratuita, uma ordem social pluralista, seja definido na Constituição como dever de subsidiar a proliferação de crenças religiosas. É preciso garantir a exclusividade das verbas públicas para as escolas da rede oficial nos termos da proposta do Fórum da Educação na Constituinte em Defesa do Ensino Público e Gratuito. Fixando um percentual mínimo da receita tributária da União, dos estados e municípios na manutenção e desenvolvimento dos sistemas oficiais de ensino, o artigo 11 desta proposta é medida fundamental para que possa efetivar-se o disposto no artigo 02:

"O ensino público, gratuito e laico em todos os níveis de escolaridade, é direito de todos os cidadãos brasileiros sem distinção de sexo, raça, idade, confissão religiosa, filiação política ou classe social. 
$\S$ único - E dever do Estado o provimento em todo o território nacional de vagas em número suficiente para atender a demanda"

Os artigos 18 e 19 da mesma proposta representam um passo importantíssimo para viabilizar uma escola pública que corresponda aos interesses populares:

- Artigo 18

"A lei regulamentará a participação da comunidade escolar (professores, estudantes, funcionários e pais), da comunidade cientifica e das entidades representativas da classe trabalhadora em organismos democraticamente constituídos para a definição e o controle da execução da política educacional em todos os niveis (federal, estadual e municipal)."

- Artigo 19

"A gestão acadêmica, científica, administrativa e financeira de todas as instituições de enisno de todos os níveis e das instituições de pesquisa, além de todos os organismos públicos de financiamento de atividades de pesquisa, extensão, aperfeicoamento de pessoal docente e desenvolvimento científico $e$ tecnológico deverá ser democrático, conforme critérios públicos e transparentes."

E através de dispositivos como estes, que incidam sobre a gestão das escolas assegurando a participação popular que é possível, sob a garantia constitucional do direito ao ensino leigo e gratuito, lutar pela construção de uma escola democrática.

\section{BIBLIOGRAFIA}

AZEVEDO, Fernando. A Cultura Brasileira. Rio de Janeiro, IBGE, 1943.

CUNHA, Nóbrega. A Revolução e a Educação. Rio de Janeiro, Oficinas do Diário de Notícias, 1932.

FERNANDES, Florestan. Educação e Constituição. Folha de S. Paulo, 4, ago. 1987.

GÓES, Moacyr. Escola Pública: História e Católicos. In: CUNHA, Luís Antônio, org. Escola Pública, Escola Particular e a democratização do ensino. São PauIo, Cortez, 1986. 
LESSA, Gustavo. O Papel dos grupos familiares na Educação. Schola. Rio de Janeiro, 1 (7), ago. 1930.

PENNA, Belisário. Solução de um Problema Vital. In: ALBERTO, Armanda Álvaro et alii. A Escola regional de Meriti. Rio de Janeiro, CBPN/INEP, 1968.

PIO XI. "A Educação cristã da juventude: carta encíclica do Papa Pio XI" Schola. Rio de Janeiro, 1 (4), maio 1930.

SILVA, Heitor Lyra. Discurso. In: OLIVEIRA, C.A. Barbosa de, org. In Memoriam Heitor Lyra da Silva. Rio de Janeiro, Mendonça Machado \& Cia., s.d.

\section{FICHA CATALOGRĀFICA}

CARVALHO, M.M.C. Pelo ensino público, leigo e gratuito. Revista da Universidade de São Paulo. São Paulo, (6): 71-83, jul./set. 1987. 